\title{
Adaptive Radiation, Ecological Opportunity, and Evolutionary Determinism
}

\section{Citation}

Losos, Jonathan B. 2010. Adaptive radiation, ecological opportunity, and evolutionary

determinism. The American Naturalist 175(6): 623-639.

\section{Published Version}

doi:10.1086/652433

\section{Permanent link}

http://nrs.harvard.edu/urn-3:HUL.InstRepos:9464287

\section{Terms of Use}

This article was downloaded from Harvard University's DASH repository, and is made available under the terms and conditions applicable to Other Posted Material, as set forth at http:// nrs.harvard.edu/urn-3:HUL.InstRepos:dash.current.terms-of-use\#LAA

\section{Share Your Story}

The Harvard community has made this article openly available.

Please share how this access benefits you. Submit a story.

Accessibility 


\title{
Adaptive Radiation, Ecological Opportunity, and Evolutionary Determinism
}

\author{
American Society of Naturalists E. O. Wilson Award Address
}

Jonathan B. Losos ${ }^{\dagger}$

Museum of Comparative Zoology and Department of Organismic and Evolutionary Biology, Harvard University, Cambridge, Massachusetts 02138

ABSTRACT: Adaptive radiation refers to diversification from an ancestral species that produces descendants adapted to use a great variety of distinct ecological niches. In this review, I examine two aspects of adaptive radiation: first, that it results from ecological opportunity and, second, that it is deterministic in terms of its outcome and evolutionary trajectory. Ecological opportunity is usually a prerequisite for adaptive radiation, although in some cases, radiation can occur in the absence of preexisting opportunity. Nonetheless, many clades fail to radiate although seemingly in the presence of ecological opportunity; until methods are developed to identify and quantify ecological opportunity, the concept will have little predictive utility in understanding a priori when a clade might be expected to radiate. Although predicted by theory, replicated adaptive radiations occur only rarely, usually in closely related and poorly dispersing taxa found in the same region on islands or in lakes. Contingencies of a variety of types may usually preclude close similarity in the outcome of evolutionary diversification in other situations. Whether radiations usually unfold in the same general sequence is unclear because of the unreliability of methods requiring phylogenetic reconstruction of ancestral events. The synthesis of ecological, phylogenetic, experimental, and genomic advances promises to make the coming years a golden age for the study of adaptive radiation; natural history data, however, will always be crucial to understanding the forces shaping adaptation and evolutionary diversification.

Keywords: adaptive radiation, contingency, ecological opportunity.

\footnotetext{
* Jonathan Losos received the 2009 E. O. Wilson Naturalist Award. The E. O. Wilson Naturalist Award is given to an active investigator in midcareer who has made significant contributions to the knowledge of a particular ecosystem or group of organisms and whose research and writing illuminate principles of evolutionary biology and an enhanced appreciation of natural history.

† E-mail: jlosos@oeb.harvard.edu.

Am. Nat. 2010. Vol. 175, pp. 623-639. (c) 2010 by The University of Chicago. 0003-0147/2010/17506-51722\$15.00. All rights reserved.

DOI: $10.1086 / 652433$
}

\section{Introduction}

Seeing this gradation and diversity of structure in one small, intimately related group of birds, one might really fancy that from an original paucity of birds in this archipelago, one species has been taken and modified for different ends. (Darwin 1845, p. 380)

The archives of natural history are filled with ... cases of species formation exploding as a response to ecological opportunity.... Natural history becomes all the more pleasing and interesting when we look at it through the lens of evolutionary theory and search for the starbursts of adaptive radiation. (Wilson 1992, p. 112)

Since Darwin's time, naturalists have been captivated by clades containing species adapted to an exceptionally broad range of ecological niches. The evolutionary exuberance of such adaptive radiations clearly reveals the power of natural selection to produce biological diversity, as Darwin realized. Further, adaptive radiations are important subjects of study, as Wilson noted, because they are systems in which the processes of adaptation and-in some cases-speciation have been greatly magnified; the outsized extent of diversification they embody may facilitate study of these processes and application to other, less diverse groups. But are adaptive radiations simply clades in which adaptive diversification has occurred to a particularly great extent, or is there something special about them, some intrinsic capacity or extrinsic compunction that has provoked evolutionary flowering not seen in other clades?

In attempting to understand the history of life, evolutionary biology is an inductive science, one in which generalities emerge not as the result of theoretical deduction or the conduct of critical experiments, but rather through the summation of many evolutionary case studies, each unique in one or many ways, from which general principles can be distinguished from exceptional counter- 
examples. In turn, a rich understanding of such case studies requires detailed and integrative studies of all facets of organismal biology, encompassing behavior, ecology, physiology, genetics, and other disciplines. The work of many of the great naturalists of our time (e.g., Edward O. Wilson and previous recipients of the Wilson Award), as well as those of times past (e.g., Jordan, Grinnell, Lack, and Mayr), has embodied this multidisciplinary perspective, which strongly emphasizes the biology of the organism in its natural environment. Adaptive radiations lend themselves to such integrative work, and detailed exploration of particular adaptive radiations-such as Darwin's finches, cichlid fishes, and Anolis lizards—not only has provided great insight into the process of evolutionary diversification but also has been instrumental in the development of many foundational ideas in the fields of ecology and evolutionary biology.

My goal in this essay is to synthesize across the many case studies of adaptive radiation, reviewing what we know about the factors that promote adaptive radiation. In the first part, I suggest that the common idea that "ecological opportunity" triggers adaptive radiation is usually correct, but that ecological opportunity is neither necessary nor sufficient for radiation to occur: theory and methods remain to be developed before we can fully understand why radiation occurs at some times and not at others. In the second half of the essay, I focus on a specific aspect of adaptive radiation, the extent to which the course it takes is predictable and deterministic.

\section{What Do We Mean by "Adaptive Radiation"?}

Darwin's insights about the evolution of Galápagos finches are mirrored in almost every definition of adaptive radiation (for a sampling of definitions, see Givnish 1997). For the purposes of this essay, I follow Futuyma in defining adaptive radiation as "evolutionary divergence of members of a single phylogenetic lineage into a variety of different adaptive forms" (Futuyma 1998, glossary). Other perspectives on adaptive radiation exist (for reviews, see Glor 2010 and Losos and Mahler 2010), but the different nuances embodied in alternative definitions do not affect the general points I discuss below.

Integral to the concept of adaptive radiation is the concept of adaptation itself. Certainly, phenotypic differences can arise for reasons other than adaptive differentiation; consequently, investigation of the adaptive basis of trait differentiation is an essential part of any study of adaptive radiation (see Arnold 1994 and Larson and Losos 1996 for reviews of adaptation and how it can be studied). For the purposes of this review, I assume that phenotypic differences among species in the radiations mentioned are, indeed, adaptively based.

\section{Ecological Opportunity: Necessary and Sufficient for Adaptive Radiation to Occur?}

What prompts adaptive radiation? The classic explanation is "ecological opportunity," which Schluter (2000, p. 69) "loosely defined as a wealth of evolutionarily accessible resources little used by competing taxa." It almost seems like a truism, but the idea is that in the presence of a variety of different types of available resources, a clade will diversify, producing a suite of species, each adapted to utilize a different portion of the resource spectrum.

Under what circumstances will a species be exposed to such a spectrum of available, little-utilized resources? Simpson (1953) was the first to lay out the prerequisites for adaptive radiation. He noted four ways in which a species could find itself in the presence of a variety of available resources.

Appearance of new resources. Evolutionary diversification of a clade may provide opportunities for other species. For example, Simpson (1953) cited the example of the evolution of grasses, which presented the ancestor of horses the opportunity to exploit and evolve within a new environmental milieu. Similarly, the origin of angiosperms may have had the same effect on weevils (McKenna et al. 2009) and ferns (Schuettpelz and Pryer 2009).

Extinction of species previously using resources. Extinction events can remove ecologically dominant species, making the resources they had utilized available to surviving species. Indeed, many clades diversify rapidly after mass extinction events, the most famous case being the diversification of many mammal and bird clades after the end-Cretaceous extinction event (reviewed in Jablonski 2001, 2005; Erwin 2007).

Colonization of an area in which resources were previously not used. Colonization of an island may provide access to resources that are usurped by other species on the mainland but are available because of the absence of those species on the island; moreover, the absence of predators may remove constraints on using habitats to which a species is not initially well adapted, facilitating niche shifts. This explanation no doubt accounts for the preponderance of the most famous adaptive radiations on remote islands.

Evolution of a trait that permits utilization of resources in ways not previously possible. The evolution of a new feature may provide the adaptive potential to utilize a resource, allowing an ancestral species to take advantage of resources it previously could not utilize and subsequently diversify in a way that was not previously possible (reviewed in Galis 2001). Such events are labeled "key innovations," although much confusion exists because the term in recent years has also been applied to the evolution of features that promote the rate of speciation (reviewed in Heard and Hauser 1995; Hunter 1998). For my purposes here, I restrict 
the term to the evolution of features that allow a taxon to interact with the environment in a novel way, thus subjecting that taxon to very different selective pressures than it had previously experienced (Baum and Larson 1991). ${ }^{1}$

Proposed examples of key innovations that triggered adaptive radiations include the evolution of wings in birds, bats, and pterosaurs; of adhesive toepads in geckos and anoles; and of pharyngeal jaws in labrid fishes. In all of these cases, the putative key innovation opened new avenues of evolutionary diversification, leading to adaptive divergence in many traits to adapt to different aspects of the environment. Flight, for example, allowed utilization of many resources not available to ancestral species, and pharyngeal jaws freed the oral jaws for adaptation to acquiring food in different ways. Again, ecological opportunity is the key to adaptive radiation; key innovations provide the evolutionary capability of taking advantage of available resources.

\section{Can Adaptive Radiation Occur in the Absence of Ecological Opportunity?}

Adaptive radiations on isolated islands and after mass extinctions are strong evidence of the importance of ecological opportunity. In recent years, the results of phylogenetic analyses of clade diversification have also been taken as evidence: the commonly detected pattern of a burst of cladogenesis early in a clade's history is often interpreted as resulting from ecological opportunity, with lower rates later in history resulting from filling of niches (e.g., Weir 2006; McPeek 2008; Phillimore and Price 2008; Rabosky and Lovette 2008); high rates of morphological diversification early in a clade's history (Harmon et al. 2003, 2008; Agrawal et al. 2009; Burbrink and Pyron 2009) or when the number of lineages inferred to have been coexisting is low (Mahler et al., forthcoming) have received the same interpretation.

But is ecological opportunity always a prerequisite for adaptive radiation? Could a clade diversify adaptively in the absence of preexisting ecological opportunity? In theory, two possibilities exist. A clade could outcompete the species previously utilizing the resources, sequentially supplanting the incumbent species as its radiation unfolds. Alternatively, a clade could create its own ecological opportunity through the course of its own radiation.

Adaptive Radiation by Competitive Replacement. The older paleontological literature is replete with suggestions of one

\footnotetext{
${ }^{1}$ As discussed below, the evolution of a feature that increases the rate of speciation (or decreases the rate of extinction) may indirectly promote adaptive radiation; however, to keep this phenomenon separate from the sense in which "key innovation" is used here, another term is needed.
}

clade supplanting another, perhaps aided by the evolution of some key feature or features that provided superior adaptation. This idea has fallen into general disfavor. Examination of the fossil record finds that evidence of competitive replacement of one clade by another is relatively weak; in most cases, the stratigraphic occurrence of the decline of one clade and the rise of the other is not consistent with this hypothesis (Benton 1996; see discussion in Jablonski 2008), although there are some exceptions, such as the rise of cheilostome bryozoans at the expense of cyclostomes (Sepkoski et al. 2000) and perhaps that of angiosperms versus gymnosperms (Lupia et al. 1999).

Evidence from studies of introduced species supports the conclusion that competitive replacement of incumbent species is probably uncommon: competition from introduced species rarely causes the extinction of native species throughout their range (as opposed to local extinctions of some populations of a species); by contrast, introduced predators and pathogens are responsible for many extinctions of native species (Davis 2003; Sax et al. 2007). If extinction of single species is unlikely to result from interspecific competition, we might conclude that in most cases, an adaptively radiating clade is not likely to supplant an entire clade of established species by outcompeting them, a view that is in agreement with the fossil record.

Can an Adaptive Radiation Be Self-Perpetuating by Creating Ecological Opportunity as It Radiates? Diversifying clades may create their own additional ecological opportunity in two ways. First, species may evolve to exploit other species within a diversifying clade: the more species that exist in a community, the more opportunities there are for a species to adapt and diversify (Whittaker 1977; Tokeshi 1999; Erwin 2008). In the context of adaptive radiation, certainly an increase in the number of species that represent different resources to be utilized could equate to increased ecological opportunity. The result is that a clade may not only radiate in response to ecological opportunity but also, through its radiation, continue to create more opportunity, thus permitting more radiation. Schluter (2000) pointed out that many classic adaptive radiations include some species that prey on other members of the clade. The implications of this finding are twofold: first, the more a clade radiates, the more it may provide resources leading to additional divergence; and second, predatory interactions, as well as competitive ones, may occur among species within an adaptive radiation. These possibilities have not been followed up with empirical studies, but a theoretical literature is developing on the evolution of complex food web relationships (e.g., Ingram et al. 2009).

An adaptively radiating clade may create opportunity in a second way, by altering ecosystem properties and creating conditions that did not previously exist. This phe- 
nomenon is now known as "ecosystem engineering," which is defined as "modifications to the environment by a species that affects resource availability for another species" (Erwin 2008, p. 304; also Jablonski 2008). Many examples of ecosystem engineering now exist, such as the physical disturbances created by large mammalian herbivores or the effects of bioturbation by burrowing marine invertebrates. Erwin (2008) reviewed the way in which such engineering can alter the evolutionary trajectory of other species in the ecosystem. Although it is plausible that such ecosystem engineers could alter or amplify the trajectory of an adaptive radiation to which they belong, no examples from nature have been proposed; the closest example to date is Harmon et al.'s (2009) demonstration that adaptive diversification in sticklebacks leads to differences in the properties of ecosystems, depending on whether they are occupied by the descendant species or by their ancestor. However, laboratory studies have demonstrated how ecosystem engineering can foster subsequent adaptive radiation; a number of laboratory studies on microbial systems have shown that the waste products of one microbial species create a food source that is then utilized by a second type that is derived from the first (reviewed in Kassen 2009).

In summary, ecological opportunity does seem to usually be a prerequisite for adaptive radiation. Clades may create their own opportunity in several different ways, but to date, few examples of such self-propagating radiations have been documented.

\section{Failure to Radiate in the Presence of Ecological Opportunity}

Yet ecological opportunity cannot be the entire story, because in its presence, some clades radiate and others do not (Wilson 1992). In the Galápagos, for example, Darwin's finches are the only birds to have diversified to any extent; some plant, insect, and mollusk groups also have radiated extensively in this archipelago, but many others have not (Jackson 1994). Similarly, in the West Indies, few taxa other than Anolis lizards have radiated to any substantial extent, even though most have been present in the West Indies as long as anoles (Crother and Guyer 1996; see Thorpe et al. 2008). In Hawaii and any other isolated island or island group, the story is the same (e.g., Zimmerman 1970; Carlquist 1974). The failure of a clade to radiate on an oceanic island, or in other situations in which ecological opportunity should exist, could occur in a number of ways.

Lack of ecological opportunity. Appropriate resources actually may not be available for some types of organisms, even on depauperate islands. Perhaps the lack of substantial radiation of warbler finches on the Galápagos is the result of the lack of discrete resources to which different warbler-like species could adapt (Grant and Grant 2008; Rundell and Price 2009).

Lack of speciation. Adaptive radiation requires both species production and diversification into different ecological niches. If for some reason a group is incapable of speciating, then adaptive radiation cannot occur, even in the presence of ecological opportunity. For example, island birds, lizards, and snails rarely speciate on islands smaller than a threshold size (Coyne and Price 2000; Losos and Schluter 2000; Losos and Parent 2009); lack of adaptive radiation on small islands that fall below this threshold may result from the inability of colonizing species to speciate.

Lack of ecological access. Early colonizers (or early radiators in the case of post-mass extinction diversification) may usurp resources, precluding diversification by later arrivals (Carlquist 1974; for an interesting counterexample, see discussion of the tropheine cichlids in Lake Tanganyika in Salzburger et al. 2005).

Lack of evolvability. Another factor that may be important in adaptive radiation is "evolvability," the ability to evolve readily into diverse forms (Schluter 2000): taxa that are limited in their ability to evolve will change more slowly or not at all, whereas those that can readily change will be able to adapt to local circumstances (Lovette et al. 2002; Arbogast et al. 2006). A variety of factors could account for differences in evolvability, including the extent to which different aspects of the phenotype can evolve independently (Vermeij 1973; Liem 1974; Cheverud 1996; Wagner and Altenberg 1996; Gerhart and Kirschner 1998; Rutherford and Lindquist 1998): species with greater modularity may be able to diversify to a greater extent than species in which phenotypic components are less independent. Behavioral and phenotypic plasticity may also be important components of evolvability by providing species with the ability to use new resources when they are encountered. Such plasticity could allow a population to persist in a habitat in which it would otherwise perish; given enough time, advantageous genetic variation subsequently may appear and spread through the population, leading to genetic adaptation to new ecological conditions (reviewed in West-Eberhard 2003). ${ }^{2}$

The observation that some clades are particularly prone to radiating (Carlquist 1974) suggests that evolv-

\footnotetext{
${ }^{2}$ For the reasons listed in this section, the evolutionary acquisition of a key innovation also might not lead to adaptive radiation, despite allowing members of a clade to interact with the environment in a novel way. For example, salamanders in the genus Aneides are characterized by a novel morphological structure of their feet that allows them to climb, in contrast to their terrestrial relatives. Although it utilizes the environment in a fundamentally different way, compared to its ancestor, Aneides has diversified little, producing only six morphologically little-differentiated species (Baum and Larson 1991). An even more extreme case would be the evolution of the features that have allowed the monotypic aardvark to adopt its termite-feeding ways unter 1998).
} 
ability may play a role in determining whether adaptive radiation occurs. For example, both Hawaiian honeycreepers and Darwin's finches have radiated extensively, as have their sister taxa on the mainland (Burns et al. 2002; Lovette et al. 2002). By contrast, two clades that have not radiated to any substantial extent despite having been present on these islands just as long, Hawaiian thrushes and Galápagos mockingbirds, belong to clades that also show little ecological and morphological disparity on the mainland (Lovette et al. 2002; Arbogast et al. 2006; Grant and Grant 2008). A corollary of this pattern is that some clades seem to diversify repeatedly on different islands, whereas others diversify rarely. For example, some clades of African cichlids radiate in many different lakes, whereas other clades never exhibit much diversification (Seehausen 2006).

In contrast, some clades that radiate on islands are not diverse elsewhere in their range, such as Tetragnatha spiders and aglycyderid weevils, which have radiated to a much greater extent in Hawaii than elsewhere (Gillespie et al. 1994; Paulay 1994; Gillespie 2002), and cichlid fish, which, despite their great diversity in lakes, have diversified to only a minor extent in most African rivers (Joyce et al. 2005). Clearly, whether adaptive radiation of clades on islands can be predicted by the diversity of their relatives elsewhere would make for an interesting study.

\section{Conclusion: Ecological Opportunity: Of Great Heuristic, but Little Predictive, Value?}

Ecological opportunity has great heuristic value for understanding why adaptive radiation occurs. Examination of many case studies strongly supports the conclusion that radiation usually results from exposure to ecological opportunity. However, it is less successful for understanding those cases in which adaptive radiation does not occur. Although a clade may fail to radiate in the presence of ecological opportunity for several reasons, an alternative explanation is that ecological opportunities were not, in fact, available.

This leads to the question, how does one quantify ecological opportunity? What data could be used to affirm that a clade had the opportunity to diversify into a variety of different ecological niches? Phylogenetic comparative studies often consider the number of species inferred to have been present or the niche space occupied, but these studies demonstrate only how one potential measure of opportunity changes during the course of a radiation, demonstrating that the rate of radiation declines as the number and variety of clade members increases ${ }^{3}$ rather than providing an assessment of the absolute extent of opportunity for a clade that has not radiated. Indeed, occurrence in an environment with few other species does not guarantee that ecological opportunity exists: resources may not be available, or the few species present may effectively usurp those resources that are present.

A quantitative metric of ecological opportunity would probably require estimating selection on an adaptive landscape (reviewed in Fear and Price 1998; Schluter 2000; Arnold et al. 2001). If, in fact, multiple distinctive and unutilized adaptive peaks were identified, one might argue that a species had the opportunity to diversify and occupy those peaks. Of course, the existence of multiple adaptive peaks in a landscape does not guarantee that selection would push a clade to diversify to produce species occupying all of these peaks: speciation must occur, either driven by selection or for some other reason, and the landscape itself will change when other species are present. Research of this type rarely has been conducted, the most thorough being studies on Darwin's finches (Schluter and Grant 1984; Schluter 2000; see also Case 1979 on Cnemidophorus lizards). Development of ideas of this sort is needed to make ecological opportunity a fully operational and predictive concept.

\section{Determinism, Contingency, and Adaptive Radiation}

The relative importance of contingent and deterministic processes in shaping evolutionary diversification has long been debated (e.g., Gould [1989, 2002] vs. Conway Morris [2003]). On one hand, ecologists have predicted that communities occurring in similar environments should exhibit similarities in structure and composition (Orians and Paine 1983; Blondel et al. 1984; Pianka 1986; Wiens 1989; Kelt et al. 1996; Losos 1996). If these communities are occupied by distantly related taxa, as is often the case on different continents, then the ecological similarity would be convergent (Schluter 1986).

On the other hand, Gould's (1989) famous "replay the tape of life" metaphor emphasizes the contingencies of history that would lead evolutionary radiations to take different paths and produce different outcomes, even if they started with an identical ancestral species in identical environments. Moreover, radiations in different places never start with identical species or occur in identical en-

\footnotetext{
${ }^{3}$ Parent and Crespi (2009) take an alternative approach, quantifying ecological opportunity for snails as the ratio of plant species to sympatric snail species across islands in the Galápagos. They show that a putative first stage in adaptive radiation-increased niche breadth—is correlated with opportunity defined in this way.
} 


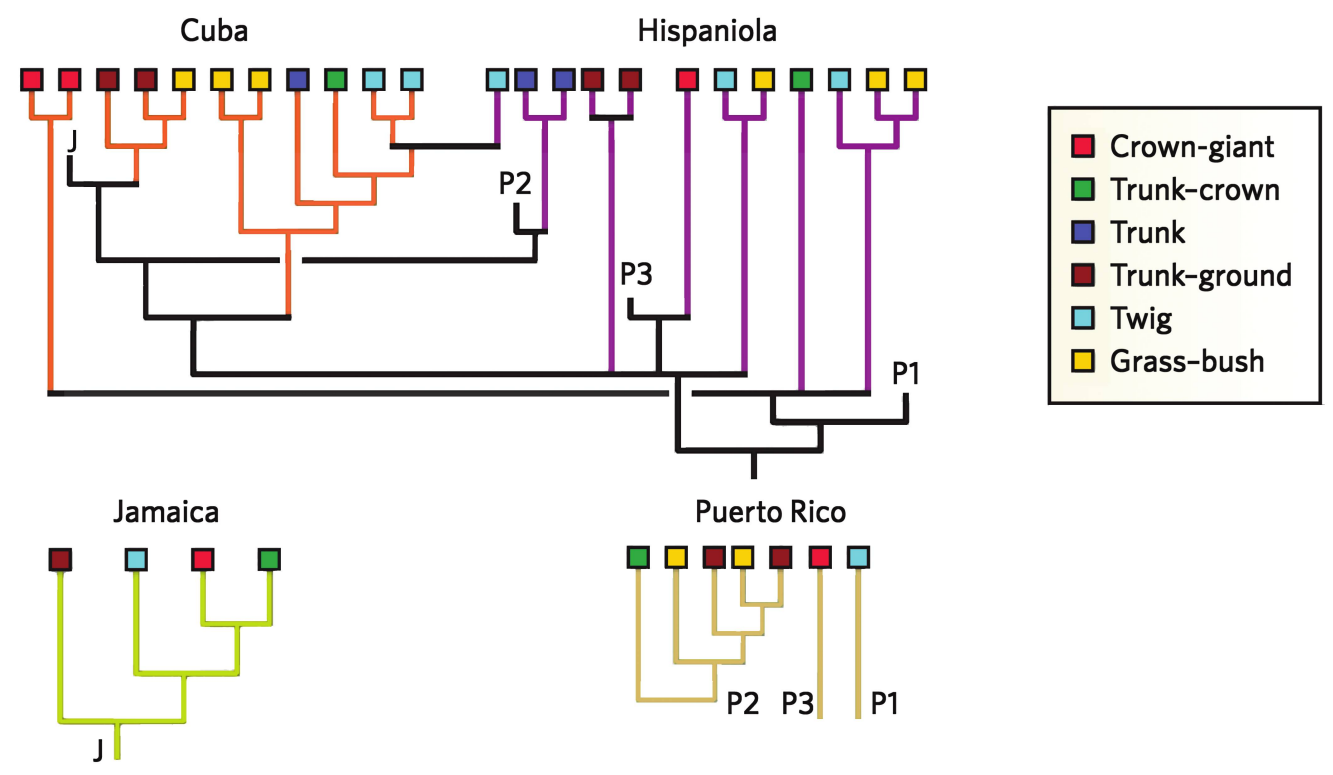

Figure 1: Convergent evolution of Anolis ecomorphs on islands in the Greater Antilles (from Losos and Ricklefs 2009).

vironments, thus providing further reason that radiations may unfold in different ways.

Evolutionary determinism could occur in adaptive radiations either by radiations producing very similar outcomes in terms of their constituent species or by radiations taking the same evolutionary path, such as always producing divergence first in one way, and then another. Both types have been proposed, but the first type of determinism may be uncommon, and evidence for the second type of determinism is equivocal.

\section{Replicated Adaptive Radiation}

In laboratory experiments, where historical contingencies can be minimized (Travisano et al. 1995; but see Blount et al. 2008), microbial systems seeded with the same starting conditions will repeatedly diversify to produce identical communities composed of the same set of two or three habitat specialists (Rainey and Travisano 1998; Meyer and Kassen 2007). In nature, however, very few examples exist of communities that are composed of species exhibiting the same set of convergently evolved phenotypes, termed "species-for-species" matching (Schluter 1990). ${ }^{4}$

Replicated adaptive radiations, when they do occur, are almost always found on islands or in lakes rather than on continents (Losos 2009). Probably the best-documented ex-

\footnotetext{
${ }^{4}$ Species-for-species implies that communities are composed of the same set of habitat specialists, with few species in any community not matched by a comparable species in the other communities.
}

ample is the fourfold replicated radiation of Anolis lizards on islands in the Caribbean (Williams 1983; reviewed in Losos 2009). On each island of the Greater Antilles (Cuba, Hispaniola, Jamaica, and Puerto Rico), anoles have radiated for the most part independently, nonetheless producing essentially the same set of habitat specialists, termed "ecomorphs" (fig. 1). Members of each ecomorph class are species that are very similar in morphology, ecology, and behavior despite their independent evolutionary origins.

Holarctic postglacial lakes exhibit the most extensive example of replicated adaptive divergence (reviewed by Schluter [2000] and Snorasson and Skúlason [2004]). In these lakes, fish have repeatedly diversified into pelagic and benthic specialists, with the pelagic planktivores tending to be smaller and more slender and possessing a greater number of gill rakers than the benthic carnivores. This divergence into benthic and pelagic ecomorphs has occurred in many types of fish, including salmon, trout, char, sticklebacks, and whitefish, in former glacial regions throughout the Northern Hemisphere; in some clades, the same pattern of divergence has occurred independently in multiple lakes (e.g., Taylor and McPhail 2000; Østbye et al. 2006; Landry et al. 2007).

The most famous case of replicated adaptive radiation is the cichlids of the Great Rift Valley in East Africa (reviewed in Fryer and Iles 1972; Stiassny and Meyer 1999; Kornfield and Smith 2000; Kocher 2004; Salzburger and Meyer 2004; Salzburger et al. 2005; Seehausen 2006; Genner et al. 2007). Approximately 2,000 species occur in lakes in this area, including extraordinary radiations that have occurred in 
Lake Tanganyika, Lake Malawi, and Lake Victoria. The faunas of these lakes have evolved independently and have each produced an extraordinary extent of ecomorphological diversity, including specialists that graze plankton, scrape algae, filter sand, or eat eggs, mollusks, or fish; and predators that use sit-and-wait or rapid-pursuit methods, pluck insect larvae from crevices, or rasp scales off the sides of other fish, to name just a few (Fryer and Iles 1972). At least some of these habitat specialists have evolved in two or all three of these lakes (Fryer and Iles 1972).

The extent of adaptive radiation of African lake cichlids is truly extraordinary, especially given the young age of the Lake Victoria radiation. In many respects, however, our understanding of replicated adaptive radiation in cichlids is limited. For example, it is unclear how common convergence is; quantitative analyses have not been conducted on the entire faunas of these lakes (Joyce et al. 2005 is a recent exception). Are the cichlid faunas of the African Great Lakes ecomorphologically matched, or do they contain only a few cases of convergence embedded in a larger sea of nonconvergence between the lakes? That is, are the cichlid faunas of these lakes like the anoles of the Greater Antilles, in which a few habitat specialist types exist only on a single island but, to a large extent, convergent speciesfor-species matches exist across islands, or are they more similar to the case of placental and marsupial mammals, in which some convergent examples exist but the faunas are overall not very similar (Losos 2009)? Fryer and Iles (1972) suggest that the latter comparison may be more apt: although some convergence has occurred, the faunas of the lakes differ in their degree of divergence and specialization, and many ecomorphological types in each lake have no match in the others.

In addition, cichlid convergence-where it does occuris primarily illustrated visually with pictures of similar fish from different lakes; these examples would be more convincing if they were supplemented by quantitative morphometric analyses demonstrating the convergent similarity (e.g., Rüber and Adams 2001; Joyce et al. 2005), as well as natural history data (e.g., functional, ecological, and behavioral) illuminating the adaptive basis for this convergence. Indeed, although such analyses of the adaptive basis for ecomorphological differentiation have been conducted for anoles (reviewed in Losos 2009) and pelagic-benthic species pairs in lakes (reviewed in Schluter 2000), most other cases of replicated adaptive radiation have not been extensively studied in this way.

Other than anoles, few examples exist of replicated adaptive radiation on islands. The best additional case is the land snail genus Mandarina in the Bonin Islands near Japan (Chiba 2004). In these snails, four types of morphologically differentiated microhabitat specialists exist: arboreal, semiarboreal, sheltered ground, and exposed ground. Phylogenetic analysis reveals that these ecomorphs have for the most

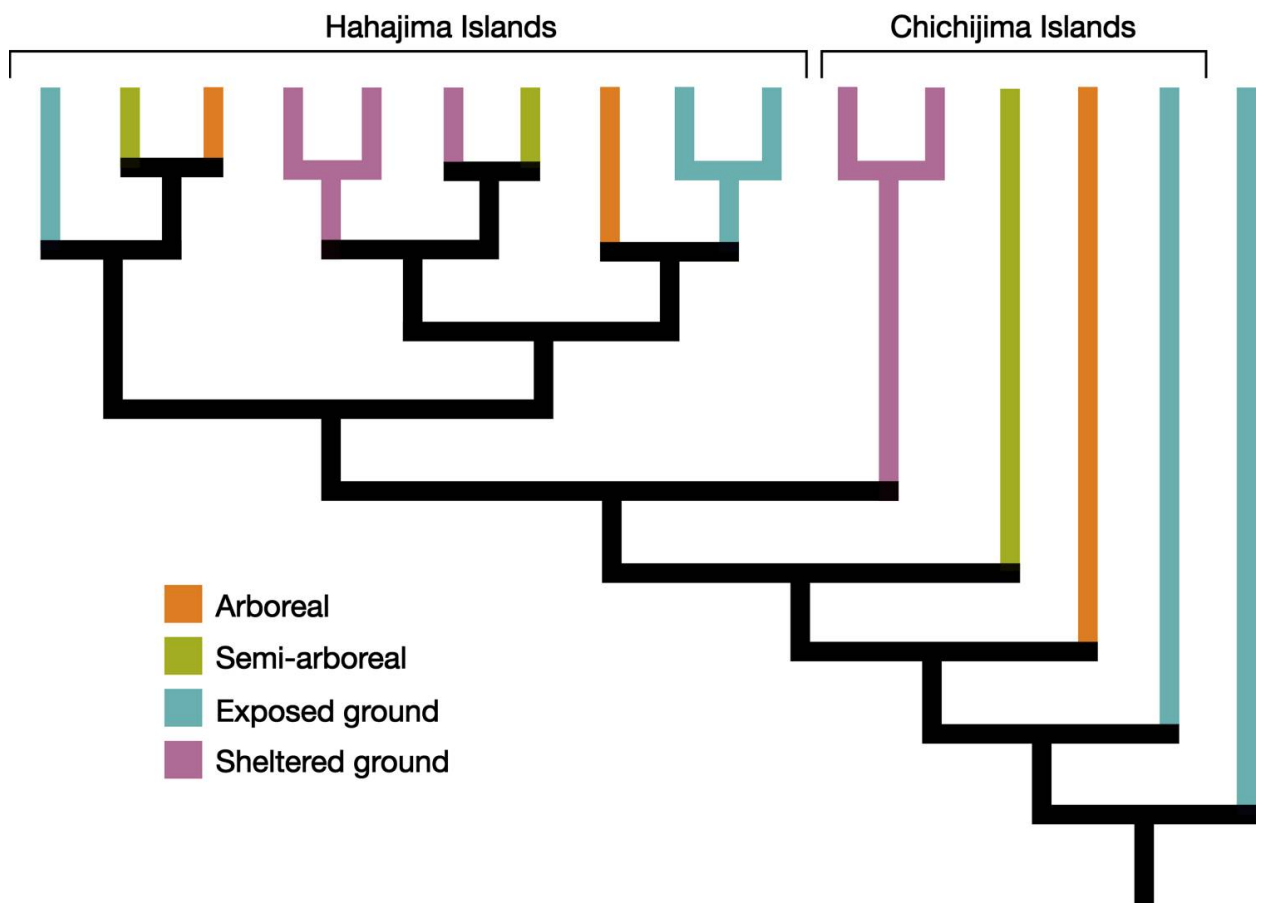

Figure 2: Convergent evolution of Mandarina snail ecomorphs in the Bonin Islands (from Losos 2009; based on Chiba 2004). 
part evolved independently multiple times among the islands, except possibly the exposed-ground ecomorph, which may be the ancestral type (fig. 2).

The spiny-leg clade of Hawaiian long-jawed spiders (Tetragnatha) provides another example (Gillespie 2004). Four microhabitat specialist types occur among these spiders: species morphologically adapted to leaf litter, moss, twigs, and bark. All the islands contain at least three of these ecomorphs; however, although some ecomorphs have evolved independently on different islands and thus are more closely related to members of different ecomorph classes on the same island, members of other ecomorph classes on different islands are closely related, indicating that these types have evolved only once or twice, with subsequent dispersal from one island to another (fig. 3). Phylogenetic reconstruction of ecomorph evolution using parsimony indicates six evolutionary transitions from one ecomorph to another and eight cases of dispersal of an ecomorph across islands (Losos 2009).

A number of generalities can be drawn from this review of replicated adaptive radiation.

Replicated Adaptive Radiation Is Rare. In light of the extent of recent study of adaptive radiation, as well as the longstanding focus among ecologists on community convergence, the paucity of well-documented cases of replicated adaptive radiation is not the result of lack of attention to this phenomenon. Additional, unexpected cases will no doubt come to light, particularly those involving diver- gence in nonmorphological characters, for which divergence within radiations and convergence among them may be harder to detect. However, the conclusion that replicated adaptive radiation is not a widespread phenomenon is unlikely to be challenged.

Replicated Adaptive Radiation Usually Occurs among Closely Related Taxa. Species-for-species matching has been noted only among relatively closely related species, such as congeneric snails and anoles (Losos 2009). One potential exception is the possibility that convergence may occur among benthic and pelagic fish in postglacial lakes around the Northern Hemisphere, even though they occur in distantly related fish families. Such matching, however, remains to be demonstrated: although divergence into benthic and pelagic ecomorphs has occurred along the same morphological axes (e.g., body size and depth and gill raker number) in many different fish families, it is not clear that all pelagic ecomorphs, regardless of ancestry, are more similar to each other than each is to their more closely related benthic counterparts. The alternative possibility is that differentiation, even though occurring in the same general way in each case, has not been great enough to erase preexisting differences among clades (Stayton 2006; Revell et al. 2007).

A good example of distant relatives radiating in different ways despite occurring in similar environmental settings is provided by comparing the adaptive radiation of day geckos (Phelsuma) on Indian Ocean islands to that of ano-

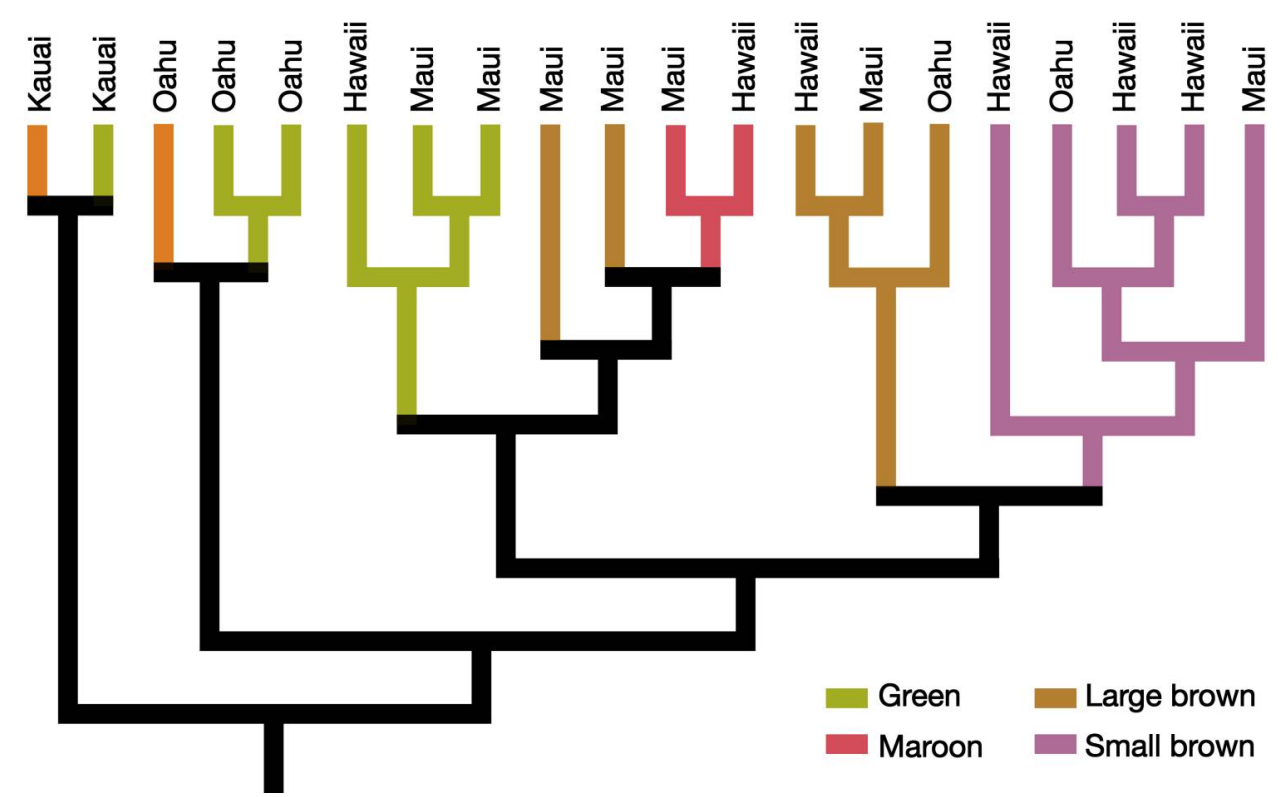

Figure 3: Evolution of Tetragnatha spider ecomorphs, illustrating both convergence and dispersal across islands (from Losos 2009; based on Gillespie 2004). 


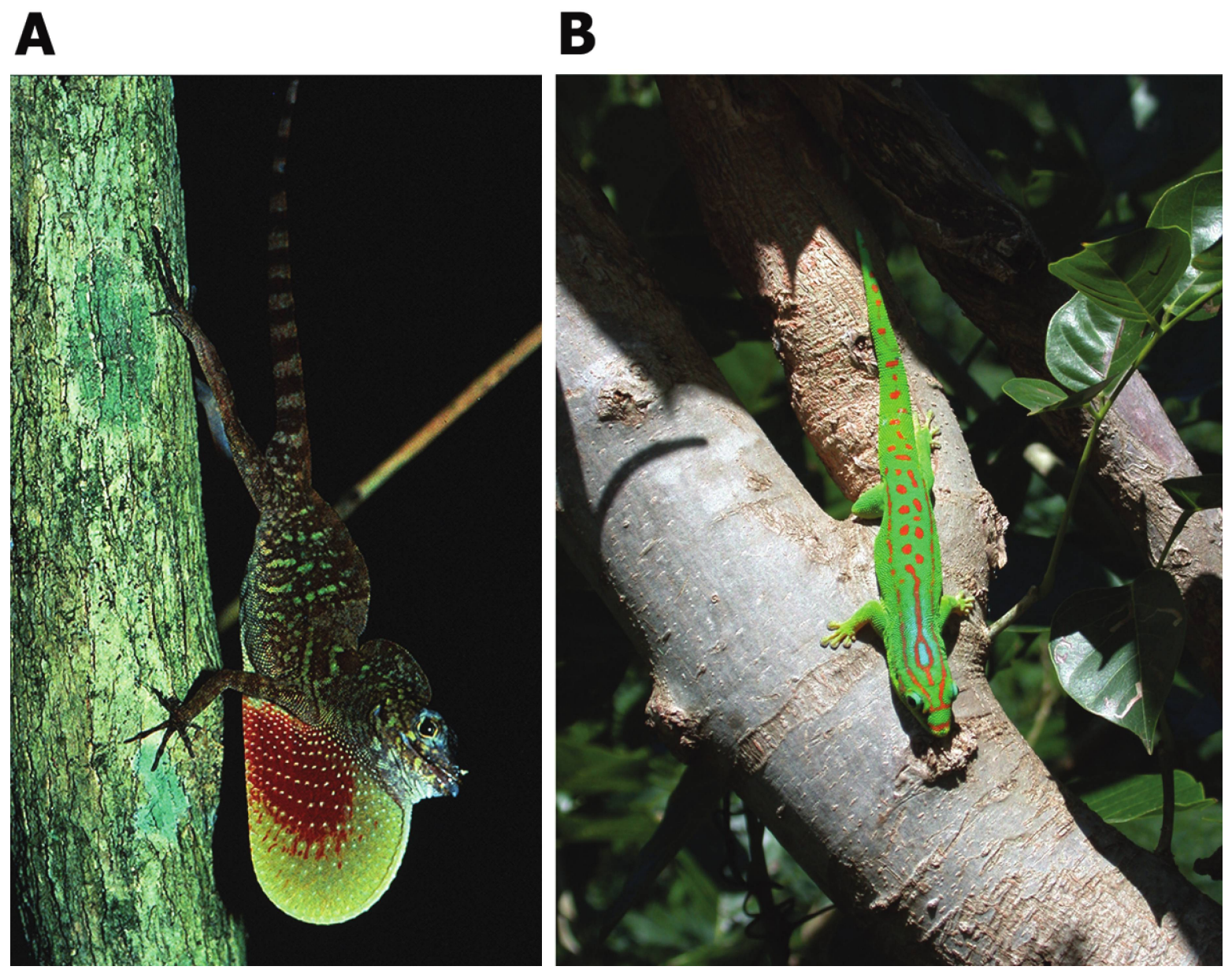

Figure 4: Anolis ahli from Cuba $(A)$ and Phelsuma guimbeaui from Mauritius $(B)$; photographs by J. B. Losos $(A)$ and Luke Harmon $(B)$.

les in the Caribbean (Losos 2009; fig. 4). Despite their nocturnal, gekkonid heritage, day geckos are similar in many ways to anoles (reviewed in Harmon et al. 2007, 2008). Being diurnal, as their name implies, they are relatively small, insectivorous, sit-and-wait-foraging, arboreal green lizards with large toepads. Also like anoles, they communicate through head movements and are highly territorial. Phelsuma has radiated independently in the Mascarene, Seychelles, and Comoros islands (Austin et al. 2004; Rocha et al. 2007; Harmon et al. 2008). Within each radiation, species have diverged ecologically and morphologically; relationships between ecology and morphology similar to those exhibited by anoles have been detected (Harmon 2005; Harmon et al. 2008). Moreover, sympatric species-of which as many as five can co-occur-partition the habitat and shift their habitat use in the presence of other species (Harmon et al. 2007).

In sum, if ever two distantly related clades would be expected to have produced replicated adaptive radiations,
Phelsuma and Anolis-separated evolutionarily by approximately 175 million years since their last common ancestor (Wiens et al. 2006) - are the ones. But the radiations are not mirror images. In comparison to anoles, Phelsuma shows only modest variation in limb or tail length, toepad size, or habitat use. In addition, in contrast to anoles, day geckos have not specialized to use narrow surfaces, such as twigs, or grassy habitats. Further unlike anoles, some large day gecko species use rocks frequently, and the largest species—now extinct-apparently was nocturnal (Vinson and Vinson 1969). Sympatric day geckos sometimes partition their habitat by tree type (palm vs. nonpalm), an ecological niche axis along which anoles never differentiate (Thorpe and Crawford 1979; Harmon et al. 2007). Overall, despite many similarities, Anolis and Phelsuma have diversified in very different ways.

Why have anoles and day geckos not motored along the same evolutionary highway? One possibility is that the island environments in which they occur may differ in 
important ways. One example is that Madagascar, the ancestral cradle of Phelsuma (Harmon et al. 2008), has nurtured another large radiation of diurnal, arboreal, and insectivorous lizards. The evolutionary radiation of chameleons-which are specialized to use narrow surfacesmay have constrained the ecological diversification of day geckos and may explain the lack of a day gecko equivalent to anoles specialized to using twigs.

Alternatively, differences in day gecko and anole diversification may have resulted from their different evolutionary potentialities. Arboreal geckos, for example, have more laterally oriented limbs than iguanid lizards, which may constrain the way geckos can adapt to different microhabitats. In addition, gecko toepads are composed of microscopic setal hairs that are elaborated much more than the relatively simple setae of anoles (Ruibal and Ernst 1965; Williams and Peterson 1982). If day geckos have greater clinging ability than anoles, as anecdotal data suggest, then divergence in limb length may not have been needed to adapt to using different microhabitats, at least not to the extent observed in anoles. These, as well as a myriad of other differences (e.g., day geckos do not have claws), may have led anole and day gecko evolution along different evolutionary routes, even if the environments in the two areas were extremely similar.

The Phelsuma-Anolis example may be representative of many similar situations: clades diversifying in apparently similar environments may exhibit very different evolutionary trajectories for two primary reasons. First, they are unlikely to occur in identical adaptive landscapes. As a generality, ecologically similar, but distantly related, clades are unlikely to radiate in the same geographic area. Consequently, such clades likely will not experience the same patterns of selection, because environments in different areas likely will differ; for example, interactions with different sets of other clades are likely to produce different evolutionary outcomes. When distantly related, but ecologically similar, clades do radiate in the same area, they likely will diversify in different ways to prevent competitive exclusion (e.g., chameleons and day geckos).

Second, clades that are distantly related differ in so many ways that entire evolutionary radiations are unlikely to unfold in the same way. The course of evolutionary diversification may depend on the starting point of a radiation (Gould's [2002, p. 1160] "happenstance of a realized beginning"): the biology of the ancestral speciesits natural history, phenotype, even its genetic variationcan influence subsequent evolutionary change (Travisano et al. 1995; Price et al. 2000; Losos 2009). Distantly related ancestral species will possess distinctive evolutionary predispositions, resulting from genomic organization, developmental systems, behavioral biology, and many other factors that will tilt evolutionary change to occur more likely in some directions than in others, especially if these constraints remain throughout the course of a clade's history (Arnold 1994; Donoghue 2005). To give an extreme example, an insectivorous mammal colonizing an oceanic island is likely to radiate in very different ways from an insectivorous lizard, even if they eat the same insects. Although even closely related species may differ, radiations initiated by distantly related species are more likely to be influenced by such differences (Price et al. 2000).

Looked at in the opposite way, closely related clades may be more likely to diversify in the same way because they share similar developmental and genetic systems. As a result, when species from such clades experience the same selective conditions, they may adapt in genetically and developmentally similar ways (Haldane 1932; Gould 2002; Hoekstra 2006). Recent studies have provided many examples in which parallel phenotypic change in closely related species (or populations of the same species) is caused by similar genetic changes in a wide range of organisms and traits (e.g., Sucena et al. 2003; Colosimo et al. 2005; Derome and Bernatchez 2006; Derome et al. 2006; Hoekstra et al. 2006; Protas et al. 2006; Shapiro et al. 2006; Whittall et al. 2006; Baxter et al. 2008; Gross et al. 2009; Chan et al. 2010; of course, this is not always the case: sometimes convergent phenotypic evolution is accomplished by different genetic changes, even in closely related species [e.g., Hoekstra and Nachman 2003; Wittkopp et al. 2003; Hoekstra et al. 2006; Kingsley et al. 2009]).

Replicated Adaptive Radiation Rarely Occurs in Radiations on Different Continents. Although examples of intercontinental convergence are legion (Conway Morris 2003), few purported cases of replicated adaptive radiations across continents have been put forth (e.g., Bossuyt and Milinkovitch 2000; Ruedi and Mayer 2001; Stadelmann et al. 2007), and the examples that have been suggested require further examination to assess the extent of species-forspecies matching (Losos 2009). Radiations occurring on different continents usually will be accomplished by distantly related clades that are, for reasons just discussed, likely to diversify in different ways (Pianka 1986; Cadle and Greene 1993; Losos 1994). In addition, clades diversifying on different continents probably will not experience identical selective pressures: for example, the different biota will lead to divergent adaptive landscapes as a result of differences in regimes of predation, competition, disease, and so on. In addition, the depauperate biota on islands may allow a single clade to radiate into wide-open ecological space; by contrast, in continental settings, ecological opportunity (perhaps resulting from the appearance of a new resource or the extinction of a previously dominant group) will provoke many clades to radiate simultaneously, limiting the opportunities available to any 


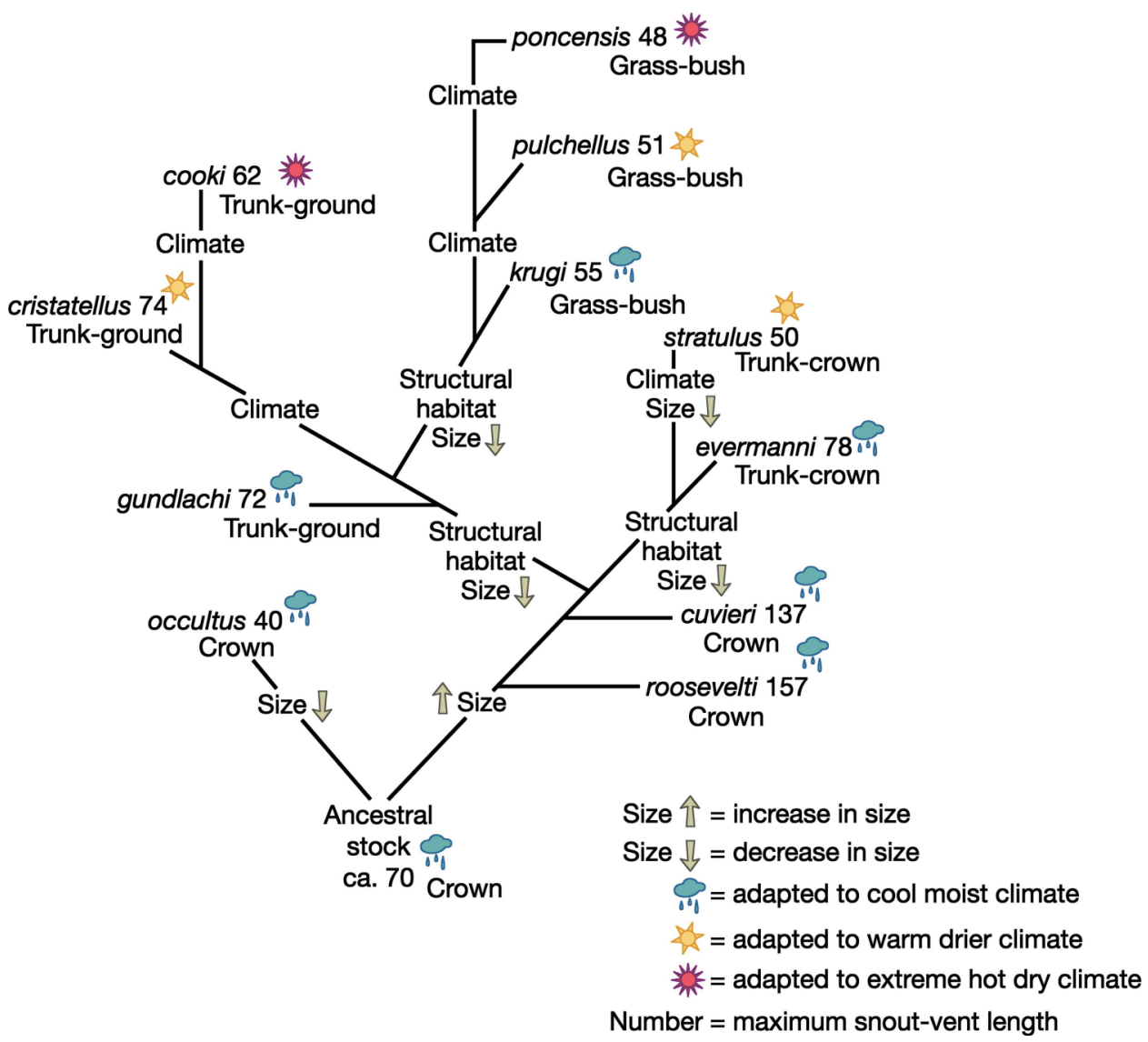

Figure 5: Stages of Anolis radiation on Puerto Rico, as envisioned by Williams (1972).

one clade. Of course, the greater number of islands than continents may also play a role in generating this pattern.

Clades Experiencing Replicated Adaptive Radiation Tend to Be Poor Dispersers. Replicated adaptive radiation in flying organisms occurs rarely, for obvious reasons. As just discussed, evolutionary replication usually occurs on multiple islands or lakes in the same general area, where environments are likely to be similar. However, species capable of moving back and forth between potential evolutionary arenas are unlikely to experience independent radiations: the faunas in the different lakes or islands may end up being very similar, but the similarity will result because the matching species are closely related, rather than representing convergent evolution (e.g., some of the Hawaiian Tetragnatha discussed above). By contrast, the poor dispersal ability of animals like lizards or frogs sets the stage for replicated adaptive radiation (see also Patterson and Givnish 2004 for an example in a continental plant clade).

\section{Stages of Radiation}

The second possible deterministic aspect of adaptive radiations concerns the manner in which they unfold: in addition to the possibility of producing the same outcome, the progression of adaptive radiations may occur in the same way. For example, Williams (1972) suggested that there were distinct stages of evolutionary diversification of anoles in Puerto Rico (fig. 5). The first stage involved divergence in body size: an ancestral anole that occurred in the shade in arboreal vegetation gave rise to three arboreal species differing in size: small, medium, and large. At that point, the canopy was full and the next stage of divergence involved change along structural microhabitat lines, producing species using the trunk-ground and grassbush niches, again in shaded microhabitats. Finally, the last stage of divergence was along the climatic axis, producing species similar in size and structural microhabitat to their ancestors, but moving from the shade to occupy hotter, more open microhabitats.

Similar scenarios have been proposed for the evolution 
of other taxa. For example, Diamond (1986) proposed that New Guinean birds diverge first in habitat type and subsequently in prey size and food type; Richman and Price (1992) suggested that leaf warblers (genus Phylloscopus) diverged first in body size, then in behavior and foraging morphology, and finally in habitat use; and Streelman et al. (2002) suggested that parrotfish diversified sequentially in habitat, diet, and sexually selected traits (reviewed by Streelman and Danley [2003] and Ackerly et al. [2006]).

These hypotheses share a common form: a clade first diversifies in one way, such as in habitat use. Once that avenue is fully utilized, diversification along that axis stops and species begin diverging along a different axis, such as prey size. Many explanations could account for the order in which axes are differentiated, including optimality considerations, genetic constraints, or historical contingencies such as the phenotype of the ancestral species or the order in which different resource types themselves became diverse enough to offer the opportunity for divergent adaptation (Diamond 1986; Schluter 2000; Gavrilets 2004; Price 2010; see also Schoener 1977).

The problem with these hypotheses is that they usually rely on phylogenetic reconstruction of ancestral traits (an exception is Diamond 1986; see discussion in Ackerly et al. 2006 and Losos 2009). Unfortunately, we are unlikely to be able to have much confidence in ancestral reconstructions for traits that evolve rapidly relative to the frequency of cladogenesis (Schluter et al. 1997; Oakley and Cunningham 2000). For example, the phylogeny for leaf warblers exhibits a basal split between two clades, one containing three large species and the other consisting of five smaller species (Richman and Price 1992). This is the type of situation in which ancestral reconstruction is likely to be most reliable, and hence the conclusion that early in their radiation leaf warblers diverged in body size is strongly supported. In contrast, species with high and low values for habitat use are found in both clades, and some of the largest differences occur between recently diverged sister taxa. In light of the evolutionary lability of this trait, we can have little confidence in phylogenetic inferences of habitat use for ancestors deep in the phylogeny. Unfortunately, this precludes testing one aspect of a stages-ofradiation hypothesis, that traits inferred to have diverged in later stages of a radiation did not also diverge early in the radiation; an alternative possibility would be that body size diverged early in the radiation without much subsequent change, but that habitat use has been diverging throughout the radiation (Ackerly et al. 2006; Price 2007). This ambiguity, in turn, makes it difficult to assess whether different adaptive radiations have diversified in the same sequence.

\section{Future Prospects}

The confluence of increased interest and advances in analytical and experimental techniques makes these exciting times for the study of adaptive radiation. The phylogenetic revolution in comparative biology is providing evidence for the existence of previously unrecognized radiations as well as providing sophisticated techniques for interpreting patterns of species diversification and phenotypic radiation (e.g., O'Meara et al. 2006; Rabosky and Lovette 2008). An important complement to this work is increasing focus on the evolution of functional capabilities, which provides the ability to investigate the adaptive aspect of phenotypic diversification (reviewed in Wainwright 2007; Losos 2009). Coupled with continuing paleontological discoveries, we are developing an ever more complete understanding of the historical patterns of adaptive radiation through time.

In turn, the study of evolutionary process, with relevance to natural selection, adaptation, and speciation, is also making rapid advances. Field studies of natural selection (e.g., Grant and Grant 2006), sometimes experimental (e.g., Losos et al. 2006), are testing the hypothesis that interspecific interactions drive adaptive diversification in adaptive radiations. Studies on nascent adaptive radiations, such as those of sticklebacks and walking sticks, are shedding light on how speciation and adaptive diversification occur in the early stages of adaptive radiation (e.g., Rundle et al. 2003; Schluter 2003; Nosil and Crespi 2006), although of course there is no guarantee that these taxa will eventually become full-blown adaptive radiations. In this light, invasive species, in so many ways potentially disastrous ecologically, may serve a positive role by creating quasi experiments that could never be conducted intentionally, allowing evolutionary biologists to study the early stages of adaptive radiation when a species arrives in an environment in which it has no previous evolutionary history (e.g., Carroll et al. 1998; Phillips and Shine 2004; Sax et al. 2007; Vellend et al. 2007). In some cases, small-scale evolutionary experiments in nature are available, and these too can be used to test hypotheses concerning adaptive radiation (Reznick and Ghalambor 2005). In addition, laboratory studies of evolutionary diversification are becoming increasingly complicated and sophisticated and are beginning to use organisms more typical of those that biologists study in the field. The power of such studies to enlighten understanding of the evolutionary process is already apparent (Kassen 2009) and will only increase in value in future years.

Finally, the explosion of information on genomes and their evolution will provide great understanding about the genetic control-in both positive and negative senses - of adaptive diversification. The increasing availability of genomic data for species in adaptive radiations (e.g., Dar- 
win's finches: Abzhanov et al. 2004, 2006) and the ability to combine detailed studies of natural selection and genomics will immeasurably advance our understanding of adaptive radiation; such work is already underway with sticklebacks (Barrett et al. 2008) and likely will soon be joined by studies on many other taxa.

For these reasons, the next decade or two promise to be a golden age in the study of adaptive radiation in particular and evolutionary biology in general. Nonetheless, in all of the excitement borne from the incredible technological capabilities we now have of examining genes and their workings, inferring patterns and processes of evolution from deep in time to the present, and manipulating organisms and environments both in the laboratory and in nature, we must not forget the central importance of knowledge of the organism in its natural habitat. More so now than ever, to fully understand how adaptive radiation and speciation conspire to produce adaptive radiation, basic data on the biology of organisms in their natural habitats are needed (Greene 2005; Grant and Grant 2008).

\section{Acknowledgments}

For extremely helpful comments on previous versions of this manuscript, I thank A. Algar, L. Harmon, L. Mahler, M. McPeek, T. Price, B. Ricklefs, D. Schluter, J. Thompson, and P. Wainwright. Thanks to L. Harmon for allowing me to use his photograph.

\section{Literature Cited}

Abzhanov, A., M. Protas, B. R. Grant, P. R. Grant, and C. J. Tabin. 2004. Bmp4 and morphological variation of beaks in Darwin's finches. Science 305:1462-1465.

Abzhanov, A., W. P. Kuo, C. Hartmann, B. R. Grant, P. R. Grant, and C. J. Tabin. 2006. The calmodulin pathway and evolution of elongated beak morphology in Darwin's finches. Nature 442:563567.

Ackerly, D. D., D. W. Schwilk, and C. O. Webb. 2006. Niche evolution and adaptive radiation: testing the order of trait divergence. Ecology 87:S50-S61.

Agrawal, A. A., M. Fishbein, R. Halitschke, A. P,. Hastings, D. L. Rabosky, and S. Rasmann. 2009. Evidence for adaptive radiation from a phylogenetic study of plant defenses. Proceedings of the National Academy of Sciences of the USA 106:18067-18072.

Arbogast, B. S., S. V. Drovetski, R. L. Curry, P. T. Boag, G. Seutin, P. R. Grant, B. R. Grant, and D. J. Anderson. 2006. The origin and diversification of Galapagos mockingbirds. Evolution 60:370382.

Arnold, E. N. 1994. Investigating the origins of performance advantage. Pages 123-168 in P. Eggleton and R. Vane-Wright, eds. Phylogenetics and ecology. Academic Press, London.

Arnold, S. J., M. E. Pfrender, and A. G. Jones. 2001. The adaptive landscape as a conceptual bridge between micro- and macroevolution. Genetica 112/113:9-32.

Austin, J. J., E. N. Arnold, and C. G. Jones. 2004. Reconstructing an island radiation using ancient and recent DNA: the extinct and living day geckoes (Phelsuma) of the Mascarene Islands. Molecular Phylogeny and Evolution 31:109-122.

Barrett, R. D. H., S. M. Rogers, and D. Schluter. 2008. Natural selection on a major armor gene in threespine stickleback. Science 322:255-257.

Baum, D. A., and A. Larson. 1991. Adaptation reviewed: a phylogenetic methodology for studying character macroevolution. Systematic Zoology 40:1-18.

Baxter, S. W., R. Papa, N. Chamberlain, S. Humphray, M. Joron, C. Morrison, R. H. ffrench-Constant, W. O. McMillan, and C. D. Jiggins. 2008. Convergent evolution in the genetic basis of Müllerian mimicry in Heliconius butterflies. Genetics 180:1567-1577.

Benton, M. J. 1996. On the nonprevalence of competitive replacement in the evolution of tetrapods. Pages 185-210 in D. Jablonski, D. H. Erwin, and J. Lipps, eds. Evolutionary paleobiology. University of Chicago Press, Chicago.

Blondel, J., F. Vuilleumier, L. F. Marcus, and E. Terouanne. 1984. Is there ecomorphological convergence among Mediterranean bird communities of Chile, California, and France? Evolutionary Biology 18:141-213.

Blount, Z. D., C. Z. Borland, and R. E. Lenski. 2008. Historical contingency and the evolution of a key innovation in an experimental population of Escherichia coli. Proceedings of the National Academy of Sciences of the USA 105:7899-7906.

Bossuyt, F., and M. C. Milinkovitch. 2000. Convergent adaptive radiations in Madagascan and Asian ranid frogs reveal covariation between larval and adult traits. Proceedings of the National Academy of Sciences of the USA 97:6585-6590.

Burbrink, F. T., and R. A. Pyron. 2009. How does ecological opportunity influence rates of speciation, extinction, and morphological diversification in New World ratsnakes (tribe Lampropeltini)? Evolution 64:934-943

Burns, K. J., S. J. Hackett, and N. K. Klein. 2002. Phylogenetic relationships and morphological diversity in Darwin's finches and their relatives. Evolution 56:1240-1252.

Cadle, J. E., and H. W. Greene. 1993. Phylogenetic patterns, biogeography, and the ecological structure of Neotropical snake assemblages. Pages 281-293 in R. E. Ricklefs and D. Schluter, eds. Species diversity in ecological communities: historical and geographical perspectives. University of Chicago Press, Chicago.

Carlquist, S. 1974. Island biology. Columbia University Press, New York.

Carroll, S. P., S. P. Klassen, and H. Dingle. 1998. Rapidly evolving adaptations to host ecology and nutrition in the soapberry bug. Evolutionary Ecology 12:955-968.

Case, T. J. 1979. Character displacement and coevolution in some Cnemidophorus lizards. Fortschritte der Zoologie 25:235-282.

Chan, Y. F., M. E. Marks, F. C. Jones, G. Villareal Jr., M. D. Shapiro, S. D. Brady, A. M. Southwick, et al. 2010. Adaptive evolution of pelvic reduction in sticklebacks by recurrent deletion of a Pitx 1 enhancer. Science 327:302-305.

Cheverud, J. M. 1996. Developmental integration and the evolution of pleiotropy. American Zoologist 36:44-50.

Chiba, S. 2004. Ecological and morphological patterns in communities of land snails of the genus Mandarina from the Bonin Islands. Journal of Evolutionary Biology 17:131-143.

Colosimo, P. F., K. E. Hosemann, S. Balabhadra, G. Villarreal Jr., M. Dickson, J. Grimwood, J. Schmutz, R. M. Myers, D. Schluter, and D. M. Kingsley. 2005. Widespread parallel evolution in sticklebacks 
by repeated fixation of ectodysplasin alleles. Science 307:19281933.

Conway Morris, S. 2003. Life's solution: inevitable humans in a lonely universe. Cambridge University Press, Cambridge.

Coyne, J. A., and T. D. Price. 2000. Little evidence for sympatric speciation in island birds. Evolution 54:2166-2171.

Crother, B. I., and C. Guyer. 1996. Caribbean historical biogeography: was the dispersal-vicariance debate eliminated by an extraterrestrial bolide? Herpetologica 52:440-465.

Darwin, C. 1845. Journal of researches into the natural history and geology of the countries visited during the voyage of $\mathrm{H}$. M. S. Beagle round the world, under the command of Capt. FitzRoy, R. N. 2nd ed. J. Murray, London.

Davis, M. A. 2003. Biotic globalization: does competition from introduced species threaten biodiversity? BioScience 53:481-489.

Derome, N., and L. Bernatchez. 2006. The transcriptomics of ecological convergence between 2 limnetic coregonine fishes (Salmonidae). Molecular Biology and Evolution 23:2370-2378.

Derome, N., P. Duchesne, and L. Bernatchez. 2006. Parallelism in gene transcription among sympatric lake whitefish (Coregonus clupeaformis Mitchill) ecotypes. Molecular Ecology 15:1239-1249.

Diamond, J. M. 1986. Evolution of ecological segregation in the New Guinea montane avifauna. Pages 98-125 in J. M. Diamond and T. J. Case, eds. Community ecology. Harper \& Row, New York.

Donoghue, M. J. 2005. Key innovations, convergence, and success: macroevolutionary lessons from plant phylogeny. Paleobiology 31(suppl.):77-93.

Erwin, D. H. 2007. Disparity: morphological pattern and developmental context. Paleontology 50:57-73.

2008. Macroevolution of ecosystem engineering, niche construction and diversity. Trends in Ecology \& Evolution 23:304310.

Fear, K. K., and T. Price. 1998. The adaptive surface in ecology. Oikos 82:440-448.

Fryer, G., and T. D. Iles. 1972. The cichlid fishes of the Great Lakes of Africa: their biology and evolution. Oliver \& Boyd, Edinburgh.

Futuyma, D. J. 1998. Evolutionary biology. 3rd ed. Sinauer, Sunderland, MA.

Galis, F. 2001. Key innovations and radiations. Pages 581-605 in G. P. Wagner, ed. The character concept in evolutionary biology. Academic Press, San Diego, CA.

Gavrilets, S. 2004. Fitness landscapes and the origins of species. Princeton University Press, Princeton. NJ.

Genner, M. J., O. Seehausen, D. H. Lunt, D. A. Joyce, P. W. Shaw, G. R. Carvalho, and G. F. Turner. 2007. Age of cichlids: new dates for ancient lake fish radiations. Molecular Biology and Evolution 24:1269-1282.

Gerhart, M., and J. Kirschner. 1998. Cells, embryos, and evolution: toward a cellular and developmental understanding of phenotypic variation and evolutionary adaptability. Blackwell, Oxford.

Gillespie, R. G. 2002. Biogeography of spiders on remote oceanic islands of the Pacific: archipelagoes as stepping stones? Journal of Biogeography 26:655-662.

- 2004. Community assembly through adaptive radiation in Hawaiian spiders. Science 303:356-359.

Gillespie, R. G., H. B. Croom, and S. R. Palumbi. 1994. Multiple origins of a spider radiation in Hawaii. Proceedings of the National Academy of Sciences of the USA 91:2290-2294.

Givnish, T. J. 1997. Adaptive radiation and molecular systematics: issues and approaches. Pages 1-54 in T. J. Givnish and K. J. Sytsma, eds. Molecular evolution and adaptive radiation. Cambridge University Press, Cambridge.

Glor, R. E. 2010. Phylogenetic approaches to the study of adaptive radiation. Annual Review of Ecology, Evolution, and Systematics (forthcoming).

Gould, S. J. 1989. Wonderful life: the Burgess Shale and the nature of history. Norton, New York.

. 2002. The structure of evolutionary theory. Harvard University Press, Cambridge, MA.

Grant, P. R., and B. R. Grant. 2006. Evolution of character displacement in Darwin's finches. Science 313:224-226.

2008. How and why species multiply: the radiation of Darwin's finches. Princeton University Press, Princeton, NJ.

Greene, H. W. 2005. Organisms in nature as a central focus for biology. Trends in Ecology \& Evolution 20:23-27.

Gross, J. B., R. Borowsky, and C. J. Tabin. 2009. A novel role for $M c 1 r$ in the parallel evolution of depigmentation in independent populations of the cavefish Astyanax mexicanus. PLoS Genetics 5(1):e1000326.

Haldane, J. B. S. 1932. The causes of evolution. Harper, London.

Harmon, L. J. 2005. Competition and community structure in day geckos (Phelsuma) in the Indian Ocean. PhD diss. Washington University, St. Louis.

Harmon, L. J., J. A. Schulte II, A. Larson, and J. B. Losos. 2003. Tempo and mode of evolutionary radiation in iguanian lizards. Science 301:961-964.

Harmon, L. J., L. L. Harmon, and C. G. Jones. 2007. Competition and community structure in diurnal arboreal geckos (genus Phelsuma) in the Indian Ocean. Oikos 116:1863-1878.

Harmon, L. J., J. Melville, A. Larson, and J. B. Losos. 2008. The role of geography and ecological opportunity in the diversification of day geckos (Phelsuma). Systematic Biology 57:562-573.

Harmon, L. J., B. Matthews, S. Des Roches, J. M. Chase, J. B. Shurin, and D. Schluter. 2009. Evolutionary diversification in stickleback affects ecosystem functioning. Nature 458:1167-1170.

Heard, S. B., and D. L. Hauser. 1995. Key evolutionary innovations and their ecological mechanisms. Historical Biology 10:151-173.

Hoekstra, H. E. 2006. Genetics, development and evolution of adaptive pigmentation in vertebrates. Heredity 97:222-234.

Hoekstra, H. E., and M. W. Nachman. 2003. Different genes underlie adaptive melanism in different populations of rock pocket mice. Molecular Ecology 12:1185-1194.

Hoekstra, H. E., R. J. Hirschmann, R. A. Bundey, P. A. Insel, and J. P. Crossland. 2006. A single amino acid mutation contributes to adaptive beach mouse color pattern. Science 313:101-104.

Hunter, J. P. 1998. Key innovations and the ecology of macroevolution. Trends in Ecology \& Evolution 13:31-36.

Ingram, T., L. J. Harmon, and J. B. Shurin. 2009. Niche evolution, trophic structure, and species turnover in model food webs. American Naturalist 174:56-67.

Jablonski, D. 2001. Lessons from the past: evolutionary impacts of mass extinctions. Proceedings of the National Academy of Sciences of the USA 98:5393-5398.

- 2005. Evolutionary innovations in the fossil record: the intersection of ecology, development and macroevolution. Journal of Experimental Zoology B 304:504-519.

- 2008. Biotic interactions and macroevolution: extensions and mismatches across scales and levels. Evolution 62:715-739.

Jackson, M. H. 1994. Galápagos: a natural history. 2nd ed. University of Calgary Press, Calgary. 
Joyce, D. A., D. H. Lunt, R. Bills, G. F. Turner, C. Katongo, N. Duftner, C. Sturmbauer, and O. Seehausen. 2005. An extant cichlid fish radiation emerged in an extinct Pleistocene lake. Nature 435:9095.

Kassen, R. 2009. Toward a general theory of adaptive radiation. Annals of the New York Academy of Sciences 1168:3-22.

Kelt, D. A., J. H. Brown, E. J. Heske, P. A. Marquet, S. R. Morton, J. W. Reid, K. A. Rogovin, and G. Shenbrot. 1996. Community structure of desert small mammals: comparisons across four continents. Ecology 77:746-761.

Kingsley, E. P., M. Manceau, C. D. Wiley, and H. E. Hoekstra. 2009. Melanism in Peromyscus is caused by independent mutations in agouti. PLoS ONE 4(7):e6435.

Kocher, T. D. 2004. Adaptive evolution and explosive speciation: the cichlid fish model. Nature Reviews Genetics 5:288-298.

Kornfield, I., and P. F. Smith. 2000. African cichlid fishes: model systems for evolutionary biology. Annual Review of Ecology and Systematics 31:163-196.

Landry, L., W. F. Vincent, and L. Bernatchez. 2007. Parallel evolution of lake whitefish dwarf ecotypes in association with limnological features of their adaptive landscape. Journal of Evolutionary Biology 20:971-984.

Larson, A., and J. B. Losos. 1996. Phylogenetic systematics of adaptation. Pages 187-220 in M. R. Rose and G. V. Lauder, eds. Adaptation. Academic Press, San Diego, CA.

Liem, K. F. 1974. Evolutionary strategies and morphological innovations: cichlid pharyngeal jaws. Systematic Zoology 22:425-441.

Losos, J. B. 1994. Historical contingency and lizard community ecology. Pages 319-333 in L. J. Vitt and E. R. Pianka, eds. Lizard ecology: historical and experimental perspectives. Princeton University Press, Princeton, NJ.

. 1996. Phylogenetic perspectives on community ecology. Ecology 77:1344-1354

. 2009. Lizards in an evolutionary tree: ecology and adaptive radiation of anoles. University of California Press, Berkeley.

Losos, J. B., and D. L. Mahler. 2010. Adaptive radiation: the interaction of ecological opportunity, adaptation, and speciation. In M. A. Bell, D. J. Futuyma, W. F. Eanes, and J. S. Levinton, eds. Evolution after Darwin: the first 150 years. Sinauer, Sunderland, MA (forthcoming).

Losos, J. B., and C. E. Parent. 2009. The speciation-area relationship. Pages 415-438 in J. B. Losos and R. E. Ricklefs, eds. The theory of island biogeography revisited. Princeton University Press, Princeton, NJ.

Losos, J. B., and R. E. Ricklefs. 2009. Adaptation and diversification on islands. Nature 457:830-836.

Losos, J. B., and D. Schluter. 2000. Analysis of an evolutionary species-area relationship. Nature 408:847-850.

Losos, J. B., T. W. Schoener, R. B. Langerhans, and D. A. Spiller. 2006. Rapid temporal reversal in predator-driven natural selection. Science 314:1111.

Lovette, I., E. Bermingham, and R. E. Ricklefs. 2002. Clade-specific morphological diversification and adaptive radiation in Hawaiian songbirds. Proceedings of the Royal Society B: Biological Sciences 269:37-42.

Lupia, R., S. Lidgard, and P. R. Crane. 1999. Comparing palynological abundance and diversity: implications for biotic replacement during the Cretaceous angiosperm radiation. Paleobiology 25:305340 .

Mahler, D. L., L. J. Revell, R. E. Glor, and J. B. Losos. Forthcoming.
Ecological opportunity and the rate of morphological evolution in the diversification of Caribbean anoles. Evolution.

Meyer, J. R., and R. Kassen. 2007. The effects of competition and predation on diversification in a model adaptive radiation. Nature 446:432-435.

McKenna, D. D., A. S. Sequeria, A. E. Marvaldi, and B. D. Farrell. 2009. Temporal lags and overlap in the diversification of weevils and flowering plants. Proceedings of the National Academy of Sciences of the USA 107:7083-7088.

McPeek, M. A. 2008. The ecological dynamics of clade diversification and community assembly. American Naturalist 172:E270-E284.

Nosil, P., and B. J. Crespi. 2006. Experimental evidence that predation promotes divergence in adaptive radiation. Proceedings of the National Academy of Sciences of the USA 103:9090-9095.

Oakley, T. H., and C. W. Cunningham. 2000. Independent contrasts succeed where ancestor reconstruction fails in a known bacteriophage phylogeny. Evolution 54:397-405.

O'Meara, B. C., C. Ane, M. J. Sanderson, and P. C. Wainwright. 2006. Testing for different rates of continuous trait evolution using likelihood. Evolution 60:922-933.

Orians, G. H., and R. T. Paine. 1983. Convergent evolution at the community level. Pages 431-458 in D. J. Futuyma and M. Slatkin, eds. Coevolution. Sinauer, Sunderland, MA.

Østbye, K., P. A. Amundsen, L. Bernatchez, A. Klemetsen, R. Knudsen, R. Kristoffersen, T. F. Naesje, and K. Hindar. 2006. Parallel evolution of ecomorphological traits in the European whitefish Coregonus lavaretus (L.) species complex during postglacial times. Molecular Ecology 15:3983-4001.

Parent, C. E., and B. J. Crespi. 2009. Ecological opportunity in adaptive radiation of Galápagos endemic land snails. American Naturalist 174:898-905.

Patterson, T. B., and T. J. Givnish. 2004. Geographic cohesion, chromosomal evolution, parallel adaptive radiations, and consequent floral adaptations in Calochortus (Calochortaceae): evidence from a cpDNA phylogeny. New Phytologist 161:253-264.

Paulay, G. 1994. Biodiversity on oceanic islands: its origin and extinction. American Zoologist 34:134-144.

Phillimore, A. B., and T. D. Price. 2008. Density-dependent cladogenesis in birds. PloS Biology 6(3):e71.

Phillips, B. L., and R. Shine. 2004. Adapting to an invasive species: toxic cane toads induce morphological change in Australian snakes. Proceedings of the National Academy of Sciences of the USA 101:17150-17155.

Pianka, E. R. 1986. Ecology and natural history of desert lizards: analyses of the ecological niche and community structure. Princeton University Press, Princeton, NJ.

Price, T. 2007. Speciation in birds. Roberts, Greenwood Village, CO. Price, T., I. J. Lovette, E. Bermingham, H. L. Gibbs, and A. D. Richman. 2000. The imprint of history on communities of North American and Asian warblers. American Naturalist 156:354-367.

Price, T. D. 2010. The roles of time and ecology in the continental radiation of the Old World leaf warblers (Phylloscopus and Seicercus). Philosophical Transactions of the Royal Society B: Biological Sciences (forthcoming).

Protas, M. E., C. Hersey, D. Kochanek, Y. Zhou, H. Wilkens, W. R. Jeffery, L. I. Zon, R. Borowsky, and C. J. Tabin. 2006. Genetic analysis of cavefish reveals molecular convergence in the evolution of albinism. Nature Genetics 38:107-111.

Rabosky, D. L., and I. J. Lovette. 2008. Density-dependent diversi- 
fication in North American wood warblers. Proceedings of the Royal Society B: Biological Sciences 275:2363-2371.

Rainey, P. B., and M. Travisano. 1998. Adaptive radiation in a heterogeneous environment. Nature 394:69-72.

Reznick, D. N., and C. K. Ghalambor. 2005. Selection in nature: experimental manipulations of natural populations. Integrative and Comparative Biology 45:456-462.

Richman, A. D., and T. Price. 1992. Evolution of ecological differences in the Old World leaf warblers. Nature 355:817-821.

Revell, L. J., M. A. Johnson, J. A. Schulte II, J. J. Kolbe, and J. B. Losos. 2007. A phylogenetic test for adaptive convergence in rockdwelling lizards. Evolution 61:2898-2912.

Rocha, S., D. Posada, M. A. Carretero, and D. J. Harris. 2007. Phylogenetic affinities of Comoroan and East African day geckos (genus Phelsuma): multiple natural colonisations, introductions and island radiations. Molecular Phylogeny and Evolution 43:685-692.

Rüber, L., and D. C. Adams. 2001. Evolutionary convergence of body shape and trophic morphology in cichlids from Lake Tanganyika. Journal of Evolutionary Biology 14:325-332.

Ruedi, M., and F. Mayer. 2001. Molecular systematics of bats of the genus Myotis (Vespertilionidae) suggests deterministic ecomorphological convergences. Molecular Phylogenetics and Evolution 21:436-448.

Ruibal, R., and V. Ernst. 1965. The structure of the digital setae of lizards. Journal of Morphology 117:271-294.

Rundell, R. J., and T. D. Price. 2009. Adaptive radiation, nonadaptive radiation, ecological speciation and nonecological speciation. Trends in Ecology \& Evolution 24:394-399.

Rundle, H. D., S. M. Vamosi, and D. Schluter. 2003. Experimental test of predation's effect on divergent selection during character displacement in sticklebacks. Proceedings of the National Academy of Sciences of the USA 100:14943-14948.

Rutherford, S. Z., and S. Lindquist. 1998. Hsp90 as a capacitor for morphological evolution. Nature 396:336-342.

Salzburger, W., and A. Meyer. 2004. The species flocks of East African cichlid fishes: recent advances in molecular phylogenetics and population genetics. Naturwissenschaften 91:277-290.

Salzburger, W., T. Mack, E. Verheyen, and A. Meyer. 2005. Out of Tanganyika: genesis, explosive speciation, key-innovations and phylogeography of the haplochromine cichlid fishes. BMC Evolutionary Biology 5:17.

Sax, D. F., J. J. Stachowicz, J. H. Brown, J. F. Bruno, M. N. Dawson, S. D. Gaines, R. K. Grosberg, et al. 2007. Ecological and evolutionary insights from species invasions. Trends in Ecology \& Evolution 22:465-471.

Schluter, D. 1986. Tests for similarity and convergence of finch communities. Ecology 67:1073-1085.

- 1990. Species-for-species matching. American Naturalist 136:560-568.

. 2000. The ecology of adaptive radiation. Oxford University Press, Oxford.

- 2003. Frequency dependent natural selection during character displacement in sticklebacks. Evolution 57:1142-1150.

Schluter, D., and P. R. Grant. 1984. Determinants of morphological patterns in communities of Darwin's finches. American Naturalist 123:175-196.

Schluter, D., T. D. Price, A. Ø. Mooers, and D. Ludwig. 1997. Likelihood of ancestor states in adaptive radiation. Evolution 51:16991711.

Schoener, T. W. 1977. Competition and the niche. Pages 35-136 in
C. Gans and D. Tinkle, eds. Biology of the Reptilia. Vol. 7. Ecology and behaviour A. Academic Press, London.

Schuettpelz, E., and K. M. Pryer. 2009. Evidence for a Cenozoic radiation of ferns in an angiosperm-dominated canopy. Proceedings of the National Academy of Sciences of the USA 106:1120011205.

Seehausen, O. 2006. African cichlid fish: a model system in adaptive radiation research. Proceedings of the Royal Society B: Biological Sciences 273:1987-1998.

Sepkoski, J. J., Jr., F. K. McKinney, and S. Lidgard. 2000. Competitive displacement among post-Paleozoic cyclostome and cheilostome bryozoans. Paleobiology 26:7-18.

Shapiro, M. D., M. A. Bell, and D. M. Kingsley. 2006. Parallel genetic origins of pelvic reduction in vertebrates. Proceedings of the National Academy of Sciences of the USA 103:13753-13758.

Simpson, G. G. 1953. The major features of evolution. Columbia University Press, New York.

Snorasson, S. S., and S. Skúlason. 2004. Adaptive speciation in northern freshwater fishes. Pages 210-228 in U. Diekmann, M. Doebeli, J. A. J. Metz, and D. Tautz, eds. Adaptive speciation. Cambridge University Press, Cambridge.

Stadelmann, B., L.-K. Lin, T. H. Kunz, and M. Ruedi. 2007. Molecular phylogeny of New World Myotis (Chiroptera, Vespertilionidae) inferred from mitochondrial and nuclear DNA genes. Molecular Phylogeny and Evolution 43:32-48.

Stayton, C. T. 2006. Testing hypotheses of convergence with multivariate data: morphological and functional convergence among herbivorous lizards. Evolution 60:824-841.

Stiassny, M. J., and A. Meyer. 1999. Cichlids of the rift lakes. Scientific American 280:64-69.

Streelman, J. T., and P. D. Danley. 2003. The stages of evolutionary radiation. Trends in Ecology \& Evolution 18:126-131.

Streelman, J. T., M. Alfaro, M. W. Westneat, D. R. Bellwood, and S. A. Karl. 2002. Evolutionary history of the parrotfishes: biogeography, ecomorphology, and comparative diversity. Evolution 56: 961-971.

Sucena, E., I. Delon, I. Jones, F. Payre, and D. L. Stern. 2003. Regulatory evolution of shavenbaby/ovo underlies multiple cases of morphological parallelism. Nature 424:935-938.

Taylor, E. B., and J. D. McPhail. 2000. Historical contingency and ecological determinism interact to prime speciation in sticklebacks, Gasterosteus. Proceedings of the Royal Society B: Biological Sciences 267:2375-2384.

Thorpe, R. S., and C. M. Crawford. 1979. The comparative abundance and resource partitioning of two green-gecko species (Phelsuma) on Praslin, Seychelles. British Journal of Herpetology 6:1924.

Thorpe, R. S., A. G. Jones, A. Malhotra, and Y. Surget-Groba. 2008. Adaptive radiation in Lesser Antillean lizards: molecular phylogenetics and species recognition in the Lesser Antillean dwarf gecko complex, Sphaerodactylus fantasticus. Molecular Ecology 17:14891504.

Tokeshi, M. 1999. Species coexistence: ecological and evolutionary perspectives. Blackwell Science, Oxford.

Travisano, M., J. A. Mongold, A. F. Bennett, and R. E. Lenski. 1995. Experimental tests of the roles of adaptation, chance, and history in evolution. Science 267:87-90.

Vellend, M., L. J. Harmon, J. L. Lockwood, M. M. Mayfield, A. R. Hughes, J. P. Wares, and D. F. Sax. 2007. Effects of exotic species 
on evolutionary diversification. Trends in Ecology \& Evolution 22: 481-488.

Vermeij, G. J. 1973. Adaptation, versatility, and evolution. Systematic Zoology 22:466-477.

Vinson, J., and J. M. Vinson. 1969. The saurian fauna of the Mascarene Islands. Mauritius Institute Bulletin 6:203-320.

Wagner, G. P., and L. Altenberg. 1996. Complex adaptations and the evolution of evolvability. Evolution 50:967-976.

Wainwright, P. C. 2007. Functional versus morphological diversity in macroevolution. Annual Review of Ecology and Systematics 38: 381-401.

Weir, J. T. 2006. Divergent timing and patterns of species accumulation in lowland and highland Neotropical birds. Evolution 60: 842-855.

West-Eberhard, M. J. 2003. Developmental plasticity and evolution. Oxford University Press, Oxford.

Whittaker, R. H. 1977. Evolution of species diversity in land communities. Evolutionary Biology 10:1-67.

Whittall, J. B., C. Voelckel, D. J. Kliebenstein, and S. A. Hodges. 2006. Convergence, constraint and the role of gene expression during adaptive radiation: floral anthocyanins in Aquilegia. Molecular Ecology 15:4645-4657.
Wiens, J. A. 1989. The ecology of bird communities. Vol. 1. Foundations and patterns. Cambridge University Press, Cambridge.

Wiens, J. J., M. C. Brandley, and T. W. Reeder. 2006. Why does a trait evolve multiple times within a clade? repeated evolution of snakelike body form in squamate reptiles. Evolution 60:123-141. Williams, E. E. 1972. The origin of faunas: evolution of lizard congeners in a complex island fauna: a trial analysis. Evolutionary Biology 6:47-89.

. 1983. Ecomorphs, faunas, island size, and diverse end points in island radiations of Anolis. Pages 326-370 in R. B. Huey, E. R. Pianka, and T. W. Schoener, eds. Lizard ecology: studies of a model organism. Harvard University Press, Cambridge, MA.

Williams, E. E., and J. A. Peterson. 1982. Convergent and alternative designs in the digital adhesive pads of scincid lizards. Science 215: 1509-1511.

Wilson, E. O. 1992. The diversity of life. Belknap, Cambridge, MA. Wittkopp, P. J., B. L. Williams, J. E. Selegue, and S. B. Carroll. 2003. Drosophila pigmentation evolution: divergent genotypes underlying convergent phenotypes. Proceedings of the National Academy of Sciences of the USA 100:1808-1813.

Zimmerman, E. C. 1970. Adaptive radiation in Hawaii with special reference to insects. Biotropica 2:32-38.

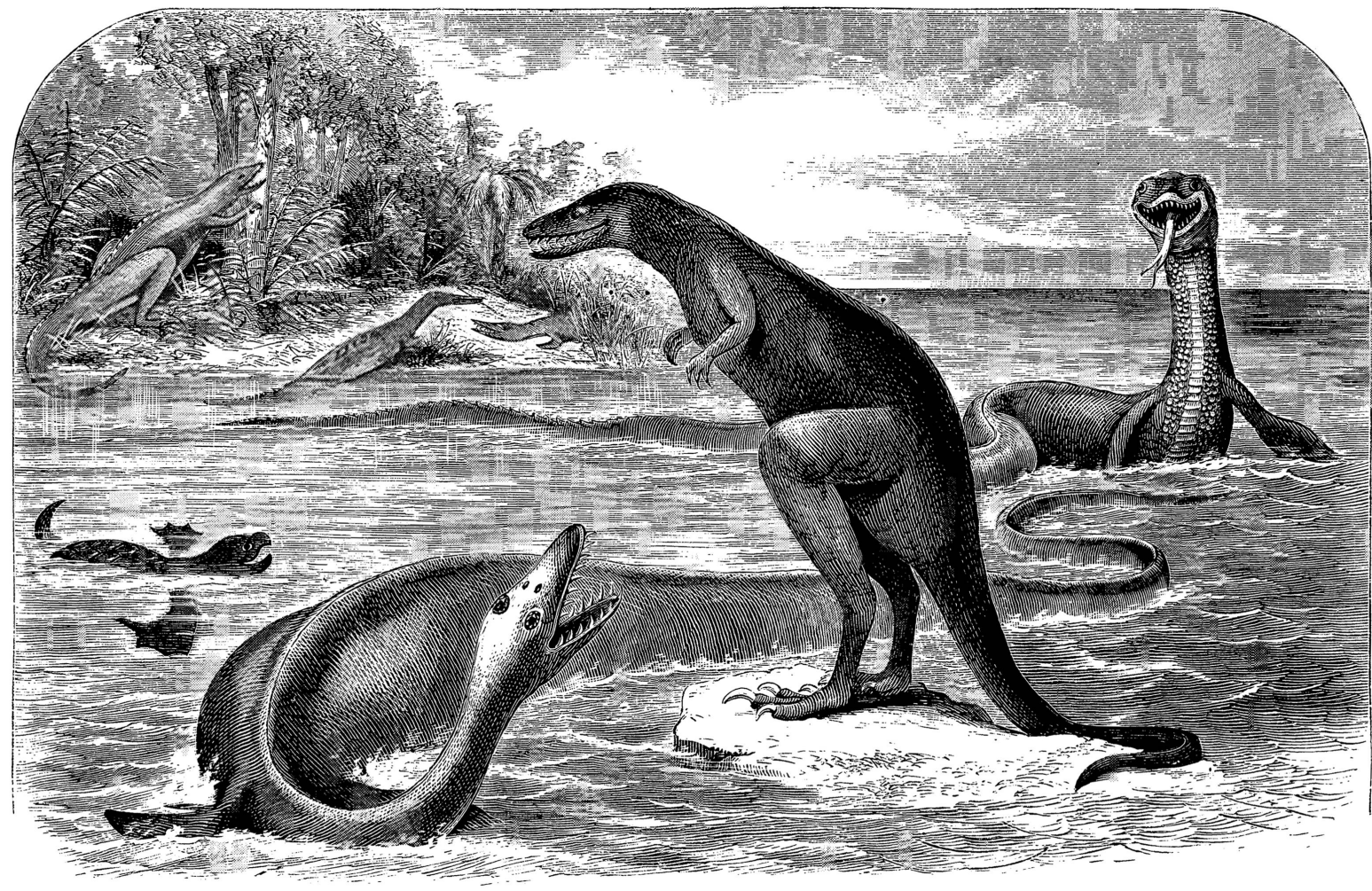

"The artist has attempted an ideal representation of a few of the subjects which haunted the shores of our country, when our prairies were the ocean bottom, and our southern and eastern borders were far beneath the Atlantic. Loelaps aquilunguis occupies the foreground on a promontory, where his progress is interrupted by the earnest protest of an Elasmosaurus. Mosasaurus watches at a distance with much curiosity and little good will, while Osteopygis views at a safe distance the unwonted spectacle. On the distant shore a pair of the huge Hadrosauri browse on the vegetation, squatting on their haunches and limbs as on a tripod. Thoracosaurus crawls up the banks with a fish, and is ready to disappear in the thicket." From "The Fossil Reptiles of New Jersey (Continued)," by E. D. Cope (American Naturalist, 1869, 3:84-91). 